\title{
The role of sideport incision in astigmatism change after cataract surgery
}

\author{
This article was published in the following Dove Press journal: \\ Clinical Ophthalmology \\ 5 August 2015 \\ Number of times this article has been viewed
}

\author{
Sofia Theodoulidou' \\ loannis Asproudis' \\ Christos Kalogeropoulos' \\ Aristidis Athanasiadis ${ }^{2}$ \\ Miltiadis Aspiotis' \\ 'Department of Ophthalmology, \\ Medical School, University of loannina, \\ loannina, Greece; ${ }^{2}$ Ophthalmology \\ Clinic, General Hospital of Piraeus \\ “Tzaneio”, Attiki, Greece
}

Purpose: To study the changes in corneal astigmatism after cataract surgery when the sideport incision is performed at a predetermined location away from the tunnel incision.

Setting: General Hospital of Piraeus “Tzaneio", Attiki, Greece.

Materials and methods: A total of 333 eyes with corneal astigmatism $\leq 1.5$ diopters (D) underwent cataract surgery. A three-step superotemporal clear corneal incision for the right eye and a superonasal clear corneal incision for the left eye $(3.0 \mathrm{~mm})$ was made, while the sideport incision was located at $<90^{\circ}, 90^{\circ}-110^{\circ}$, and $>110^{\circ}$. Keratometric data were measured with corneal topography EyeSys Vista 2000 pre- and postoperatively at the 1st and 6th month. Surgically induced astigmatism was calculated by vector analysis. We noted all cases in which a change $>0.5 \mathrm{D}$ in corneal astigmatic power occurred, as well as a change $>20^{\circ}$ in axis torque, despite axis direction.

Results: After multiple logistic regression analysis was conducted, cases with $>110^{\circ}$ distance between the tunnel and sideport incision had 2.22 times $(P=0.021)$ greater likelihood for having changed $>0.5 \mathrm{D}$ in astigmatic power at the 1 st month and 3.45 times $(P=0.031)$ at the 6th month postoperatively, as compared with cases with a $90^{\circ}-110^{\circ}$ distance between the tunnel and sideport incision. As for the change in the astigmatic axis, cases with $<90^{\circ}$ distance had a 4.18 times greater likelihood for having a change $>20^{\circ}(P<0.001)$ (preoperative to 1 st month) as compared with cases having $90^{\circ}-110^{\circ}$ of distance.

Conclusion: For surgeons that operate only from the superior position, we propose that in order to produce an incision that is as "astigmatically neutral" as possible, they should perform the sideport incision at a $90^{\circ}-110^{\circ}$ distance.

Keywords: cataract surgery, astigmatism, sideport incision, tunnel incision

\section{Introduction}

Small incision cataract surgery is considered a refractive surgery, targeting early visual rehabilitation and emmetropia. With the development of new technologies in the manufacturing of intraocular lenses and the introduction of new generation algorithms in biometry, eye surgeons are able to fully correct the spherical component of the refractive error. The correction of preoperative astigmatism is challenging since different factors affect preexisting astigmatism. Incision size (width and length) and configuration (one-, two-, and three-step), incision location relative to the limbus, and the axis on which the main incision was performed ${ }^{1-5}$ are the parameters that a surgeon can impact in order to change (or not change) preoperative astigmatism. Factors such as the eye (left or right), ${ }^{6,7}$ corneal pachymetry, ${ }^{8}$ the magnitude of preoperative astigmatism, ${ }^{9}$ and the type of astigmatism (with the rule [WTR], against the rule $[\mathrm{ATR}])^{10}$ are parameters that we take into account when planning cataract surgery, but that we cannot interfere with in order to change corneal refractive status.
Correspondence: Sofia Theodoulidou Department of Ophthalmology, Medical School, University of loannina, Nosokomeiou 14, Aegina 18010, Attiki, Greece

Tel +30 6973007374

Fax +30 2I 05698667

Email sofou30@yahoo.gr 
The purpose of this study is to introduce the distance between tunnel and sideport incision as a factor affecting postoperative astigmatism and to evaluate the forces that act to change the cornea. A small incision temporally positioned is thought to be, by most surgeons, "astigmatically neutral" when compared with a superotemporal, superonasal, or superior incision. ${ }^{3,11-13} \mathrm{We}$ propose a certain distance between a tunnel and sideport incision so that our main incision, when it is performed from above the patients' head, will minimally affect postoperative corneal astigmatism.

\section{Materials and methods}

This observational study was performed at the General Hospital of Piraeus "Tzaneio", Attiki, Greece, from February 2011 to October 2013. The study was approved by the hospital's ethics committee and was performed in accordance with the ethical principles of the Declaration of Helsinki. Written informed consent was obtained from each patient.

In this research, 333 patients were included. All eyes presented with a corneal astigmatism $\leq 1.5$ diopters (D). Preoperative exclusion criteria were previous anterior segment surgery, dry eye syndrome, chronic use of eye drops, and corneal pathology, such as epithelial or stromal lesions, scars, endothelial guttata, and a horizontal corneal diameter $<11.5 \mathrm{~mm}$ and $>12.5 \mathrm{~mm}$. Moreover, all cases of unrecordable corneal topography, big differences between serial measurements, a dilated pupil diameter smaller than $5.5 \mathrm{~mm}$, and cataract grading (according to the Lens Opacities Classification System [LOCS] III) of NC5NO5 or NC6NO6 served as factors delaying cataract surgery, further stressing the main incisions that were excluded. Postoperative exclusion criteria were suturing of the incisions, complicated surgery necessitating enlargement of the tunnel incision, bad incisions leading to ballooning, wound burn, unstable anterior chamber or tight fit around the phaco probe, iris prolapse (posteriorly placed incision), corneal distortion due to an anteriorly placed incision, and a superficial incision.

Preoperatively, all patients underwent visual acuity and biomicroscopic examination, intraocular pressure measurement with Goldmann applanation tonometry, and fundoscopy with a dilated pupil. Biometry was performed with A-scan ultrasound. Keratometric data were obtained by corneal topography EyeSys Vista 2000.

Preoperatively, on the slit lamp, axes at $90^{\circ}, 180^{\circ}$, and $0^{\circ}$ were marked as reference axes with a surgical marker in the seated position by turning the light beam coaxially in order to avoid cyclotorsion in the supine position. ${ }^{14-16}$ The location of the tunnel incision was marked at $100^{\circ}-130^{\circ}$.
Sideport incision location was preoperatively marked on the slit lamp, depending on the assigned group. In cases where the distance between the tunnel and sideport incision was $<90^{\circ}$, the tunnel incision was located at $100^{\circ}-130^{\circ}$ and the sideport incision was located at $30^{\circ}-50^{\circ}$. In cases where the distance is $>110^{\circ}$, the sideport incision was located at $350^{\circ}-10^{\circ}$. We chose to refer to the incisions as degrees of arc because our incisions were of a certain width. In a mean $12.0 \mathrm{~mm}$ diameter cornea, the width of a $3.0 \mathrm{~mm}$ tunnel incision corresponds to $28.66^{\circ}-30^{\circ}$ and a $1.0 \mathrm{~mm}$ sideport incision corresponds to $9.55^{\circ}-10^{\circ}$, respectively. Intraoperatively, we determined the location of the incisions using a classic Mendez ring. The axes of the incisions were postoperatively confirmed on the slit lamp.

Postoperative follow up was scheduled on the 1st day, 1 st month, and 6th month after surgery. Biomicroscopy at the slit lamp, where the axis of the tunnel and sideport incisions were reported by turning the light beam coaxially to the tunnel and sideport incisions, was performed.

Also, the best corrected visual acuity using Snellen optotype and corneal topography were performed. Surgically induced astigmatism (SIA) was calculated by vector analysis using Alpin's method. All cases that presented with a change over $0.5 \mathrm{D}$ in corneal astigmatic power and over $20^{\circ}$ in the astigmatic axis, independent of the direction of torque, were studied. Of note, $0^{\circ}-25^{\circ}$ and $155^{\circ}-180^{\circ}$ was considered as ATR astigmatism and $65^{\circ}-115^{\circ}$ was considered as WTR astigmatism. Eyes with oblique astigmatism were excluded because of their small number.

\section{Surgical technique}

All patients underwent phacoemulsification with the "horizontal chopping" technique using Sovereign with WhiteStar (Abbott Medical Optics Inc, Santa Ana, CA, USA). All surgeries were performed by one surgeon (AA). Tetracaine hydrochloride $0.5 \%$ drops were installed for topical anesthesia. A three-step clear corneal incision $(3.0 \mathrm{~mm})$ was made in the superotemporal region for the right eye and superonasal region for the left eye (at $100^{\circ}-130^{\circ}$ ).

The anterior chamber was reformed with medium viscosity sodium hyaluronate $1.5 \%$ (La Lon; LA Labs, Los Angeles, CA, USA) for the protection of the corneal endothelium and iris. A continuous curvilinear capsulorhexis was created with Utrata forceps. A stab sideport incision $(1.0 \mathrm{~mm})$ was made a predetermined distance away from the main incision $\left(<90^{\circ}, 90^{\circ}-110^{\circ}\right.$, or $\left.>110^{\circ}\right)$ followed by hydrodissection and hydrodelineation. Complete nucleus removal was followed by aspiration of the cortex and injection of a foldable 
hydrophilic acrylic three-piece intraocular lens. All eyes were under medication therapy with a combination of tobramycindexamethasone and nepafenac ophthalmic drops four times per day for 1 month.

\section{Statistical analysis}

Quantitative variables were expressed as the mean values (SD) and/or median value, while qualitative variables were expressed as absolute and relative frequencies. The Kolmogorov-Smirnov test was used to test for normality. Student's paired $t$-tests were used for comparisons of preoperative and postoperative measures between the left and right eyes. For the comparison of proportions, chi-squared and Fisher's exact tests were used. Repeated measurements analysis of variance (ANOVA) was adopted to evaluate the changes observed in SIA according to distance between the tunnel and sideport incision over the follow-up period. Bonferroni correction was used in order to control for multiple testing. Multiple logistic regression analyses were used to test the effects of the type of astigmatism and the distance between the tunnel and sideport incision on a change of over $0.5 \mathrm{D}$ in astigmatic power or a change of over $20^{\circ}$ in the astigmatic axis. In order to test whether the effect of distance between the tunnel and sideport incisions on a change over $0.5 \mathrm{D}$ in astigmatic power or change over $20^{\circ}$ in the astigmatic axis was different from or consistent with the different types of astigmatism, the interaction of the variables was tested in the logistic regression models. Odds ratios (OR) with 95\% confidence intervals $(\mathrm{CI})$ were computed from the results of the logistic regression analyses. All reported $P$-values are two-tailed. Statistical significance was set at $P<0.05$ and the analyses were conducted using SPSS statistical software (version 19.0; IBM Corporation, Armonk, NY, USA).

\section{Results}

Of a total of 333 treated eyes, 25 were excluded because of surgical complications or bad incisions, and the rest of the 308 eyes were followed postoperatively (158 left and 150 right eyes). The mean age of the patients was 72.6 years ( $\mathrm{SD}=9.1$ years) and $46.4 \%$ of these individuals were males. The distribution of the left and right eyes, according to the distance between the tunnel and sideport incisions, is shown in Table 1. Table 2 presents the differences in preoperative and postoperative measures of corneal astigmatic power between the left and right eyes.

Repeated measurements ANOVA was adopted to evaluate the changes observed in SIA according to the distance between the tunnel and sideport incisions over
Table I Distribution of the left and right eyes according to the distance between the tunnel and sideport incision

\begin{tabular}{|c|c|c|}
\hline $\begin{array}{l}\text { Distance between } \\
\text { tunnel and sideport }\end{array}$ & $\begin{array}{l}\text { Left eyes } \\
(N=158)\end{array}$ & $\begin{array}{l}\text { Right eyes } \\
(\mathrm{N}=150)\end{array}$ \\
\hline incisions & $\mathbf{N}(\%)$ & $\mathbf{N}(\%)$ \\
\hline Group A: $<90^{\circ}$ & $43(27.2)$ & $54(36.0)$ \\
\hline Group B: $90^{\circ}-110^{\circ}$ & $75(47.5)$ & $60(40.0)$ \\
\hline Group C: $>110^{\circ}$ & $40(25.3)$ & $36(24.0)$ \\
\hline
\end{tabular}

the follow-up period, separately, in the left and right eyes. SIA changes between the 1st and 6th postoperative month according to the distance between the tunnel and sideport incisions are shown in Table 3. In Table 4, the postoperative corneal astigmatic power measures at the 1st and 6th month according to the distance between the tunnel and sideport incisions are presented.

Cases where changes over $0.5 \mathrm{D}$ in astigmatic power and over $20^{\circ}$ in the astigmatic axis were found, according to the distance between the tunnel and sideport incisions - separately for the left and right eyes - are presented in Table 5; cases further considering the type of astigmatism (WTR, ATR) are presented in Table 6 . The proportion of left eyes where the change over $0.5 \mathrm{D}$ in astigmatic power from preoperative measures to the 1st month were found to be significantly greater in cases where the distance between the tunnel and sideport incisions was $<90^{\circ}$ or $>110^{\circ}$, as compared with cases where the distance between tunnel and sideport incisions was from $90^{\circ}-110^{\circ}$. Furthermore, a change over $20^{\circ}$ in the astigmatic axis from preoperative measures to the 1 st month was significantly greater in cases where the distance between tunnel and sideport incisions was $<90^{\circ}$ or $>110^{\circ}$, as compared with cases where the distance between the tunnel and sideport incisions was from $90^{\circ}-110^{\circ}$.

When multiple logistic regression analysis was conducted (Table 7) with the dependent variable (the presented change over $0.5 \mathrm{D}$ in astigmatic power [preoperative to 1st month]), and after adjusting for the eye (right or left), it was found that cases with a $>110^{\circ}$ distance between the tunnel and sideport incisions had a 2.22 times greater

Table 2 Differences in preoperative and postoperative measures of corneal astigmatic power between the left and right eyes

\begin{tabular}{|c|c|c|c|c|c|}
\hline & \multicolumn{2}{|c|}{ Left eyes } & \multicolumn{2}{|c|}{ Right eyes } & \multirow[t]{2}{*}{$P^{*}$} \\
\hline & Mean & SD & Mean & SD & \\
\hline Preoperative astigmatism & 1.04 & 0.86 & 1.12 & 0.78 & 0.359 \\
\hline Postoperative astigmatism (I month) & $|.3|$ & 0.92 & 1.23 & 0.77 & 0.408 \\
\hline Postoperative astigmatism (6 months) & I.14 & 0.90 & 1.20 & 0.80 & 0.545 \\
\hline
\end{tabular}


Table 3 Changes in SIA measures according to distance between tunnel and sideport incision

\begin{tabular}{|c|c|c|c|}
\hline & \multicolumn{2}{|l|}{ SIA } & \multirow[t]{3}{*}{$P * *$} \\
\hline & Ist month ${ }^{\dagger}$ & 6th month ${ }^{\dagger}$ & \\
\hline & Mean (SD) & Mean (SD) & \\
\hline \multicolumn{4}{|l|}{ Left eyes } \\
\hline \multicolumn{4}{|c|}{ Distance between the tunnel and sideport incisions } \\
\hline Group A: $<90^{\circ}$ & $0.8 \mathrm{I}(0.53)$ & $0.73(0.52)$ & 0.004 \\
\hline Group B: $100^{\circ}-110^{\circ}$ & $0.64(0.36)$ & $0.62(0.38)$ & 0.218 \\
\hline Group C: $>110^{\circ}$ & $0.79(0.39)$ & $0.72(0.46)$ & 0.020 \\
\hline$P^{*}(A$ versus $B)$ & 0.114 & 0.569 & \\
\hline$P^{*}(\mathrm{~A}$ versus $\mathrm{C})$ & 1.000 & 1.000 & \\
\hline$P^{*}(\mathrm{~B}$ versus $\mathrm{C})$ & 0.225 & 0.686 & \\
\hline \multicolumn{4}{|l|}{ Right eyes } \\
\hline \multicolumn{4}{|c|}{ Distance between the tunnel and sideport incisions } \\
\hline Group A: $<90^{\circ}$ & $0.8(0.53)$ & $0.72(0.52)$ & 0.005 \\
\hline Group B: $100^{\circ}-110^{\circ}$ & $0.58(0.36)$ & $0.6(0.37)$ & 0.440 \\
\hline Group C: $>110^{\circ}$ & $0.73(0.36)$ & $0.7(0.31)$ & 0.370 \\
\hline$P^{*}(A$ versus $B)$ & 0.020 & 0.353 & \\
\hline$P^{*}(A$ versus $C)$ & 1.000 & 1.000 & \\
\hline$P^{*}$ (B versus $\left.C\right)$ & 0.290 & 0.761 & \\
\hline
\end{tabular}

Notes: *Group effect; **time effect. ${ }^{\dagger}$ Changes at Ist and 6 th postoperative months. Bold type indicates values with statistical significance.

Abbreviation: SIA, surgically induced astigmatism.

likelihood of exhibiting a change over $0.5 \mathrm{D}$ in astigmatic power (preoperative to 1 st month) as compared with cases with a $90^{\circ}-110^{\circ}$ distance between the tunnel and sideport incisions. Also, it was found that WTR cases were less likely to have a change over $0.5 \mathrm{D}$ in astigmatic power (preoperative to 1 st month) in comparison with the ATR cases. Multiple analyses for a change over $0.5 \mathrm{D}$ in astigmatic power (preoperative to the 6th month) showed that cases with a $>110^{\circ}$ distance between the tunnel and sideport incisions had a 3.45 times greater likelihood of exhibiting a change over $0.5 \mathrm{D}$ in astigmatic power (preoperative to the 6th month), as compared with cases with a $90^{\circ}-110^{\circ}$ distance between the tunnel and sideport incisions. In terms of the change in the corneal astigmatic axis, it was found that cases with $\mathrm{a}<90^{\circ}$ distance between the tunnel and sideport incisions had a 4.18 times greater likelihood of exhibiting a change over $20^{\circ}$ in the astigmatic axis (preoperative to the 1st month), as compared with cases with a $90^{\circ}-110^{\circ}$ distance. Furthermore, during multiple analyses, it was found that WTR cases were less likely to have a change over $20^{\circ}$ in the astigmatic axis (preoperative to the 6th month) in comparison with ATR cases. The interaction of distance between the tunnel and sideport incisions with type of astigmatism was not significant in any of the logistic models, indicating that the effect of distance between the tunnel and sideport incisions was similar in the two types of astigmatism.

\section{Discussion}

The factors affecting corneal astigmatism in cataract surgery are those related to the eye (right or left, corneal diameter, and power and type of astigmatism), the incision (size, location, and configuration), and the surgical technique (microincision cataract surgery, small incision cataract surgery,

Table 4 Corneal astigmatic power measures preoperatively at the Ist and 6th month according to the distance between the tunnel and sideport incisions

\begin{tabular}{|c|c|c|c|c|}
\hline & \multirow{3}{*}{$\begin{array}{l}\text { Preoperative corneal } \\
\text { astigmatic power } \\
\text { Mean (SD) }\end{array}$} & \multicolumn{2}{|c|}{ Postoperative corneal astigmatic power } & \multirow[t]{3}{*}{$P * *$} \\
\hline & & \multirow{2}{*}{$\frac{\text { Ist month }}{\text { Mean (SD) }}$} & \multirow{2}{*}{$\begin{array}{l}\text { 6th month } \\
\text { Mean (SD) }\end{array}$} & \\
\hline & & & & \\
\hline \multicolumn{5}{|l|}{ Left eyes } \\
\hline \multicolumn{5}{|c|}{ Distance between tunnel and sideport incisions } \\
\hline Group A: $<90^{\circ}$ & I.0I (0.79) & $1.30(0.76)$ & $1.05(0.79)$ & 0.004 \\
\hline Group B: $100^{\circ}-110^{\circ}$ & $0.96(0.72)$ & $1.19(0.84)$ & $1.07(0.74)$ & 0.084 \\
\hline Group C: $>110^{\circ}$ & $1.12(0.99)$ & $1.55(1.17)$ & $1.36(1.22)$ & 0.041 \\
\hline$P^{*}(A$ versus $B)$ & & 1.000 & 1.000 & \\
\hline$P^{*}(A$ versus $C)$ & & 0.638 & 0.322 & \\
\hline$P^{*}(B$ versus $C)$ & & 0.138 & 0.301 & \\
\hline \multicolumn{5}{|l|}{ Right eyes } \\
\hline \multicolumn{5}{|c|}{ Distance between tunnel and sideport incisions } \\
\hline Group A: $<90^{\circ}$ & $1.13(0.78)$ & $1.24(0.84)$ & $1.15(0.76)$ & 0.179 \\
\hline Group B: $100^{\circ}-110^{\circ}$ & $\mathrm{I} .17(0.8 \mathrm{I})$ & $1.26(0.78)$ & $1.28(0.84)$ & 0.690 \\
\hline Group C: $>110^{\circ}$ & $1.03(0.72)$ & $1.16(0.69)$ & $1.13(0.83)$ & 0.695 \\
\hline$P^{*}(A$ versus $B)$ & & 1.000 & 1.000 & \\
\hline$P^{*}(\mathrm{~A}$ versus $\mathrm{C})$ & & 1.000 & 1.000 & \\
\hline$P^{*}$ (B versus $\left.C\right)$ & & 1.000 & 1.000 & \\
\hline
\end{tabular}

Notes: $* P$-value for group effect; ${ }^{* * P}$-value for time effect. Bold type indicates values with statistical significance. 
Table 5 Changes over $0.5 \mathrm{D}$ in astigmatic power and over $20^{\circ}$ on the astigmatic axis according to the distance between the tunnel and sideport incisions, separately for the left and right eyes

\begin{tabular}{|c|c|c|c|c|}
\hline & \multirow{3}{*}{$\begin{array}{l}\text { Change in } \\
\text { astigmatic } \\
\text { power/axis }\end{array}$} & \multicolumn{3}{|c|}{ Distance between tunnel and sideport incisions } \\
\hline & & $\begin{array}{l}\text { Group A: } \\
<90^{\circ}\end{array}$ & $\begin{array}{l}\text { Group B: } \\
90^{\circ}-110^{\circ}\end{array}$ & $\begin{array}{l}\text { Group C: } \\
>110^{\circ}\end{array}$ \\
\hline & & $\mathbf{N}(\%)$ & $\mathbf{N}(\%)$ & $\mathbf{N}(\%)$ \\
\hline \multicolumn{5}{|l|}{ Left eyes } \\
\hline \multirow[t]{2}{*}{ Change over $0.5 \mathrm{D}$ in astigmatic power (preoperative to the Ist month) } & No & $28(65.1)$ & $61(81.3)$ & $23(57.5)$ \\
\hline & Yes & $15(34.9)^{\mathrm{B}}$ & $14(18.7)^{A, C}$ & $17(42.5)^{B}$ \\
\hline \multirow[t]{2}{*}{ Change over $0.5 \mathrm{D}$ in astigmatic power (preoperative to the 6th month) } & No & $43(100.0)$ & $70(93.3)$ & $34(85.0)$ \\
\hline & Yes & $0(0.0)^{\mathrm{C}}$ & $5(6.7)$ & $6(15.0)^{\mathrm{A}}$ \\
\hline \multirow[t]{2}{*}{ Change over $20^{\circ}$ on astigmatic axis (preoperative to the Ist month) } & No & $31(72.1)$ & $64(85.3)$ & $33(82.5)$ \\
\hline & Yes & $12(27.9)$ & II (I4.7) & $7(17.5)$ \\
\hline \multirow{2}{*}{ Change over $20^{\circ}$ on the astigmatic axis (preoperative to the 6th month) } & No & $31(72.1)$ & $56(74.7)$ & $33(82.5)$ \\
\hline & Yes & $12(27.9)$ & $19(25.3)$ & $7(17.5)$ \\
\hline \multicolumn{5}{|l|}{ Right eyes } \\
\hline \multirow[t]{2}{*}{ Change over $0.5 \mathrm{D}$ in astigmatic power (preoperative to the Ist month) } & No & $42(77.8)$ & $50(83.3)$ & $30(83.3)$ \\
\hline & Yes & $12(22.2)$ & $10(16.7)$ & $6(16.7)$ \\
\hline \multirow[t]{2}{*}{ Change over $0.5 \mathrm{D}$ in astigmatic power (preoperative to the 6th month) } & No & $49(90.7)$ & $56(93.3)$ & $31(86.1)$ \\
\hline & Yes & $5(9.3)$ & $4(6.7)$ & $5(13.9)$ \\
\hline \multirow[t]{2}{*}{ Change over $20^{\circ}$ in the astigmatic axis (preoperative to the Ist month) } & No & $42(77.8)$ & $60(100.0)$ & $32(88.9)$ \\
\hline & Yes & $12(22.2)^{\mathrm{B}}$ & $0(0.0)^{A, C}$ & $4(I I . I)^{B}$ \\
\hline \multirow[t]{2}{*}{ Change over $20^{\circ}$ in the astigmatic axis (preoperative to the 6 th month) } & No & $44(81.5)$ & $46(76.7)$ & $27(75)$ \\
\hline & Yes & $10(18.5)$ & $14(23.3)$ & $9(25)$ \\
\hline
\end{tabular}

Notes: ${ }^{A, B}, C$ Significant differences in astigmatic power and axis can be found in groups $A, B$, and $C(P<0.05)$.

coaxial, and biaxial). There is growing literature regarding the changes in astigmatism after cataract surgery. ${ }^{1-13}$ However, most studies fail to account for the multitude of related factors.

A main incision of standard size and location (superotemporal region for the right eye and superonasal region for the left eyes; three-step; clear corneal; $3.0 \mathrm{~mm}$ ) and a sideport incision at different predetermined distances from the main incision $\left(<90^{\circ}, 90^{\circ}-110^{\circ},>110^{\circ}\right)$ were performed. The site of the main incision was determined by two factors. First, the surgeon was superior position right handed. Second, it is a fact that in different regions, the corneal thickness differs. For example, the inferotemporal cornea is considered to be the thinnest region. ${ }^{17,18} \mathrm{In}$ order to eliminate confounding factors that could affect postoperative astigmatism, we preferred to perform the tunnel incision in a standard location and classifies the eyes into right and left, so as to eliminate the different regional corneal thicknesses and distances from the optical center of the cornea. Each group was further classified in WTR and ATR astigmatism. Eyes with oblique astigmatism were excluded due to a limited sample, which would preclude a safe analysis.

Moreover, we included eyes with 11.5-12.5 mm horizontal corneal diameter because, considering that the cornea is a sphere and using the well-known $2 \pi \rho$ formula, a corneal diameter of $11.0 \mathrm{~mm}$ has a $34.54 \mathrm{~mm}$ perimeter, while a corneal diameter of $13.0 \mathrm{~mm}$ has a $40.82 \mathrm{~mm}$ perimeter. Since our main incision is $3.0 \mathrm{~mm}$ in width, a smaller cornea would be more affected. ${ }^{19}$ Furthermore, in small corneas, the main incision is located closer to the optical center in comparison with a large cornea. This means that there is a bigger influence in postoperative astigmatism. Thus, we created three groups; in each one, the only variable factor was the distance between the incisions. We then studied the changes in corneal astigmatic power and axis.

Gauss's law of elastic domes states that "for every change in curvature in one meridian, there is an equal and opposite change $90^{\circ}$ away". ${ }^{20}$ Our hypothesis was based on Cravy's modification of Gauss's law, in which compression in one axis results in an equal expansion in the other axis. ${ }^{21,22}$ This is also known as the coupling effect, where corneal incisions change the balance of forces, redistribute the tension vectors, and lead to flattening of the incisional meridian, with simultaneous bending of the orthogonal meridian.

According to Alpins and Walsh, "there is no such thing as a completely astigmatically neutral incision". ${ }^{23}$ Any incision, no matter how small, will still affect the corneal structure and alter the astigmatic magnitude and/or direction. ${ }^{23}$ 
Table 6 Changes over $0.5 \mathrm{D}$ in astigmatic power and over $20^{\circ}$ in the astigmatic axis according to the distance between tunnel and sideport incisions and the type of astigmatism, separately for the left and right eyes

\begin{tabular}{|c|c|c|c|c|c|c|c|}
\hline & \multirow{3}{*}{$\begin{array}{l}\text { Change in } \\
\text { astigmatic } \\
\text { power/axis }\end{array}$} & \multicolumn{6}{|c|}{ Distance between tunnel and sideport incisions } \\
\hline & & \multicolumn{2}{|c|}{$<90^{\circ}$} & \multicolumn{2}{|c|}{$90^{\circ}-110^{\circ}$} & \multicolumn{2}{|c|}{$>110^{\circ}$} \\
\hline & & $\mathbf{N}$ & $\%$ & $\overline{\mathbf{N}}$ & $\%$ & $\mathbf{N}$ & $\%$ \\
\hline \multicolumn{8}{|l|}{ Left eyes (ATR) } \\
\hline Change over $0.5 \mathrm{D}$ in astigmatic power & No & 15 & 57.7 & 29 & 76.3 & 6 & 35.3 \\
\hline (preoperative to the Ist month) & Yes & 11 & 42.3 & 9 & 23.7 & 11 & 64.7 \\
\hline Change over $0.5 \mathrm{D}$ in astigmatic power & No & 26 & 100 & 35 & 92.1 & 12 & 70.6 \\
\hline (preoperative to the 6th month) & Yes & 0 & 0 & 3 & 7.9 & 5 & 29.4 \\
\hline Change over $20^{\circ}$ in the astigmatic axis & No & 20 & 76.9 & 33 & 86.8 & 16 & 94.1 \\
\hline (preoperative to the Ist month) & Yes & 6 & 23.1 & 5 & 13.2 & I & 5.9 \\
\hline Change over $20^{\circ}$ in the astigmatic axis & No & 18 & 69.2 & 26 & 68.4 & 15 & 88.2 \\
\hline (preoperative to the 6th month) & Yes & 8 & 30.8 & 12 & 31.6 & 2 & 11.8 \\
\hline \multicolumn{8}{|l|}{ Left eyes (WTR) } \\
\hline Change over $0.5 \mathrm{D}$ in astigmatic power & No & 13 & 76.5 & 32 & 86.5 & 17 & 73.9 \\
\hline (preoperative to the Ist month) & Yes & 4 & 23.5 & 5 & 13.5 & 6 & 26.1 \\
\hline Change over $0.5 \mathrm{D}$ in astigmatic power & No & 17 & 100 & 35 & 94.6 & 22 & 95.7 \\
\hline (preoperative to the 6th month) & Yes & 0 & 0 & 2 & 5.4 & 1 & 4.3 \\
\hline Change over $20^{\circ}$ in the astigmatic axis & No & 11 & 64.7 & 31 & 83.8 & 17 & 73.9 \\
\hline (preoperative to the Ist month) & Yes & 6 & 35.3 & 6 & 16.2 & 6 & 26.1 \\
\hline Change over $20^{\circ}$ in the astigmatic & No & 13 & 76.5 & 30 & 81.1 & 18 & 78.3 \\
\hline axis (preoperative to the 6th month) & Yes & 4 & 23.5 & 7 & 18.9 & 5 & 21.7 \\
\hline \multicolumn{8}{|l|}{ Right eyes (ATR) } \\
\hline Change over $0.5 \mathrm{D}$ in astigmatic power & No & 29 & 76.3 & 30 & 85.7 & 14 & 82.4 \\
\hline (preoperative to the Ist month) & Yes & 9 & 23.7 & 5 & 14.3 & 3 & 17.6 \\
\hline Change over $0.5 \mathrm{D}$ in astigmatic power & No & 34 & 89.5 & 34 & 97.1 & 15 & 88.2 \\
\hline (preoperative to the 6th month) & Yes & 4 & 10.5 & 1 & 2.9 & 2 & 11.8 \\
\hline Change over $20^{\circ}$ in the astigmatic axis & No & 26 & 68.4 & 35 & 100 & 15 & 88.2 \\
\hline (preoperative to the Ist month) & Yes & 12 & 31.6 & 0 & 0 & 2 & 11.8 \\
\hline Change over $20^{\circ}$ in the astigmatic axis & No & 28 & 73.7 & 21 & 60 & 9 & 52.9 \\
\hline (preoperative to the 6th month) & Yes & 10 & 26.3 & 14 & 40 & 8 & 47.1 \\
\hline \multicolumn{8}{|l|}{ Right eyes (WTR) } \\
\hline Change over $0.5 \mathrm{D}$ in astigmatic power & No & 13 & 81.3 & 20 & 80 & 16 & 84.2 \\
\hline (preoperative to the Ist month) & Yes & 3 & 18.8 & 5 & 20 & 3 & 15.8 \\
\hline Change over $0.5 \mathrm{D}$ in astigmatic power & No & 15 & 93.8 & 22 & 88 & 16 & 84.2 \\
\hline (preoperative to the 6th month) & Yes & I & 6.3 & 3 & 12 & 3 & 15.8 \\
\hline Change over $20^{\circ}$ in the astigmatic axis & No & 16 & 100 & 25 & 100 & 17 & 89.5 \\
\hline (preoperative to the Ist month) & Yes & 0 & 0 & 0 & 0 & 2 & 10.5 \\
\hline Change over $20^{\circ}$ in the astigmatic axis & No & 16 & 100 & 25 & 100 & 18 & 94.7 \\
\hline (preoperative to the 6th month) & Yes & 0 & 0 & 0 & 0 & 1 & 5.3 \\
\hline
\end{tabular}

Abbreviations: ATR, against the rule; D, diopters; WTR, with the rule.

We assume that the sideport incision, despite its small width, still promotes changes in corneal curvature. When the distance between the main and sideport incision is $90^{\circ}-100^{\circ}$, a mutual neutralization of the corneal forces occurs. ${ }^{24-26}$

In right eyes, the main incision is performed superotemporally and the sideport incision is performed nasally. Since nasal incisions affect astigmatism more than temporal incisions, ${ }^{13,27}$ we assume that this is valid for sideport incisions as well, despite their smaller width. This means that in right eyes, the mutual neutralization phenomenon would lead to a lesser astigmatic change when compared with the left eye (in which case, the main incision is done superonasally and the sideport incision is done temporally). This is confirmed by findings in other studies, in which the left eyes are more affected than the right eyes. ${ }^{6,7}$

Changes in corneal astigmatism $>0.5 \mathrm{D}$ and changes in the astigmatic axis $>20^{\circ}$ are observed in cases when the incision distance is $<90^{\circ}$ and $>110^{\circ}$. It is a fact that most surgeons generally prefer to perform the sideport incision at a $\leq 90^{\circ}$ distance from the main incision for easier handling of the surgical instruments during the phacoemulsification stage. When the distance between incisions is $<90^{\circ}$ 
Table 7 Results from multiple logistic regression analysis with the dependent variables presented as changes of over $0.5 \mathrm{D}$ in astigmatic power and over $20^{\circ}$ in the astigmatic axis

\begin{tabular}{|c|c|c|}
\hline & OR $(95 \% \mathrm{CI}) *$ & $\boldsymbol{P}$-value** \\
\hline \multicolumn{3}{|c|}{$\begin{array}{l}\text { Change over } 0.5 \mathrm{D} \text { in astigmatic power (preoperative } \\
\text { to the Ist month) }\end{array}$} \\
\hline \multicolumn{3}{|c|}{ Type of astigmatism } \\
\hline ATR & 1.00 & \\
\hline WTR & $0.55(0.31-0.96)$ & 0.037 \\
\hline \multicolumn{3}{|c|}{ Distance between the tunnel and sideport incisions } \\
\hline$<90^{\circ}$ & $1.84(0.97-3.49)$ & 0.064 \\
\hline $90^{\circ}-110^{\circ}$ & 1.00 & \\
\hline$>110^{\circ}$ & $2.22(1.13-4.35)$ & 0.021 \\
\hline \multicolumn{3}{|c|}{ Change over $0.5 \mathrm{D}$ in astigmatic power (preoperative } \\
\hline \multicolumn{3}{|c|}{ to the 6th month) } \\
\hline \multicolumn{3}{|c|}{ Type of astigmatism } \\
\hline ATR & 1.00 & \\
\hline WTR & $0.72(0.30-1.69)$ & 0.447 \\
\hline \multicolumn{3}{|c|}{ Distance between the tunnel and sideport incisions } \\
\hline$<90^{\circ}$ & 1.00 & \\
\hline $90^{\circ}-110^{\circ}$ & $1.42(0.46-4.42)$ & 0.545 \\
\hline$>110^{\circ}$ & $3.45(1.12-10.63)$ & 0.031 \\
\hline \multicolumn{3}{|c|}{ Change over $20^{\circ}$ in the astigmatic axis (preoperative } \\
\hline \multicolumn{3}{|c|}{ Type of astigmatism } \\
\hline ATR & 1.00 & \\
\hline WTR & $1.01(0.52-1.97)$ & 0.972 \\
\hline \multicolumn{3}{|c|}{ Distance between the tunnel and sideport incisions } \\
\hline$<90^{\circ}$ & $4.18(1.9-9.2)$ & $<0.001$ \\
\hline $90^{\circ}-110^{\circ}$ & 1.00 & \\
\hline$>110^{\circ}$ & $1.97(0.8-4.83)$ & 0.139 \\
\hline \multicolumn{3}{|c|}{ Change over $20^{\circ}$ in the astigmatic axis (preoperative } \\
\hline \multicolumn{3}{|c|}{ to the 6th month) } \\
\hline \multicolumn{3}{|c|}{ Type of astigmatism } \\
\hline ATR & 1.00 & \\
\hline WTR & $0.30(0.16-0.54)$ & $<0.001$ \\
\hline \multicolumn{3}{|c|}{ Distance between the tunnel and sideport incisions } \\
\hline$<90^{\circ}$ & $0.81(0.43-1.53)$ & 0.509 \\
\hline $90^{\circ}-110^{\circ}$ & 1.00 & \\
\hline$>110^{\circ}$ & $0.92(0.46-1.85)$ & 0.811 \\
\hline
\end{tabular}

Notes: *OR $(95 \% \mathrm{Cl})$ adjusted for the eye (right or left); **indicates the reference category.

Abbreviations: D, diopters; OR, odds ratio; $\mathrm{Cl}$, confidence interval; ATR, against the rule; WTR, with the rule. (or $>110^{\circ}$ ), the bending forces act on different axes and affect the power of astigmatism and/or produce a greater torque of the astigmatism axis, as shown by our results. The disparity in the axis of the cylinder between the operated and the non-operated eye leads to meridional aniseikonia, which is poorly tolerated by the patient.

A temporal main incision is considered as "astigmatically neutral" due to the greater distance from the optical corneal center, the lesser wound stress produced by the phacoprobe, ${ }^{27,28}$ and the thinner cornea at that site. ${ }^{17,18}$ For right-handed surgeons that operate only from the superior position (above the patient's head), we propose that in order to produce an incision that is as astigmatically neutral as possible, they should perform a sideport incision at the $90^{\circ}-110^{\circ}$ distance from the main incision (Figure 1). This way, one avoids augmentation of the astigmatic power, and it also maintains the corneal enantiomorphism between the left and right eyes ${ }^{29}$ thanks to the lesser torque of the astigmatic axis.

A limitation of our study is the use of anterior surface corneal topography and the unavailability of pachymetry. Thin corneas are related to more corneal deformation or SIA after cataract surgery. Knowing the corneal thickness gives us the opportunity to exclude another factor that could affect our results - in this case, very thin or thick corneas.

\section{Conclusion}

In the future, we propose that cases with greater astigmatism and different main incision locations are studied, taking into consideration corneal pachymetry. Also, some surgeons make two sideport incisions and a further study may show which has the ideal distance between these three incisions. In this way, we can better elucidate the corneal biomechanics, thus enabling us to formulate a better surgical plan.
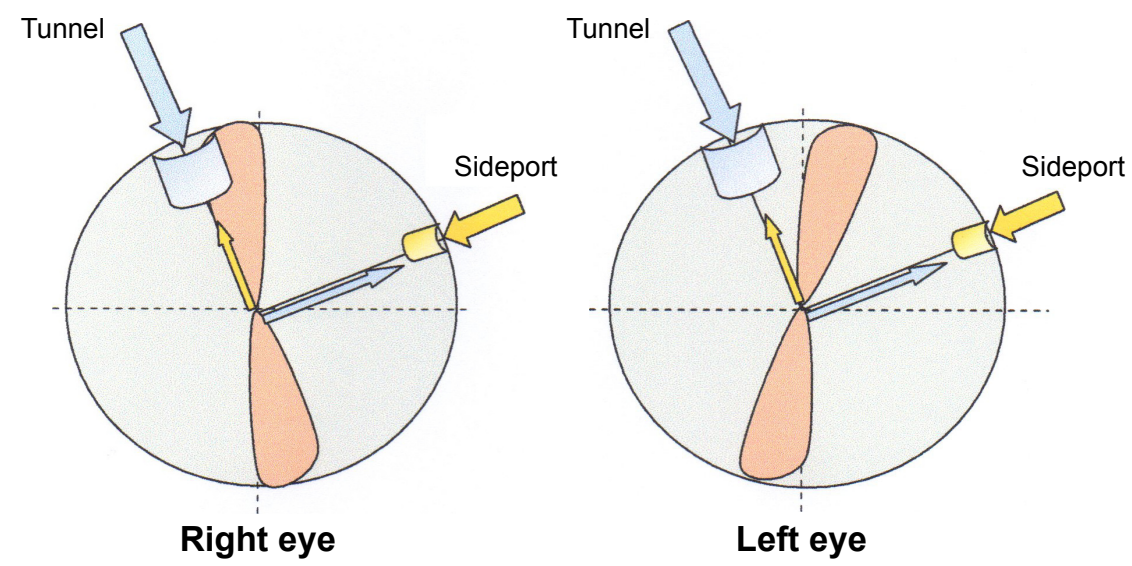

Figure I Proper location of the tunnel and sideport incisions for the right-handed superior position surgeon preserving corneal enantiomorphism. 


\section{Disclosure}

The authors report no conflicts of interest in this work.

\section{References}

1. Borasio E, Mehta JS, Maurino V. Torque and flattening effects of clear corneal temporal and on-axis incisions for phacoemulsification. $J$ Cataract Refract Surg. 2006;32(12):2030-2038.

2. Wei YH, Chen WL, Su PY, Shen EP, Hu FR. The influence of corneal wound size on surgically induced corneal astigmatism after phacoemulsification. J Formos Med Assoc. 2012;111(5):284-289.

3. Merriam JC, Zheng L, Merriam JE, Zaider M, Lindström B. The effect of incisions for cataract on corneal curvature. Ophthalmology. 2003; 110(9):1807-1813.

4. Matsumoto Y, Hara T, Chiba K, Chikuda M. Optimal incision sites to obtain an astigmatism-free cornea after cataract surgery with a $3.2 \mathrm{~mm}$ sutureless incision. J Cataract Refract Surg. 2001;27(10): $1615-1619$.

5. Moon SC, Mohamed T, Fine IH. Comparison of surgically induced astigmatisms after clear corneal incisions of different sizes. Korean $J$ Ophthalmol. 2007;21(1):1-5.

6. Ermiş SS, Inan UU, Oztürk F. Surgically induced astigmatism after superotemporal and superonasal clear corneal incisions in phacoemulsification. J Cataract Refract Surg. 2004;30(6):1316-1319.

7. Ozkurt Y, Erdoğan G, Güveli AK, et al. Astigmatism after superonasal and superotemporal clear corneal incisions in phacoemulsification. Int Ophthalmol. 2008;28(5):329-332.

8. Woo SJ, Lee JH. Effect of central corneal thickness on surgically induced astigmatism in cataract surgery. J Cataract Refract Surg. 2003; 29(12):2401-2046.

9. Tejedor J, Murube J. Choosing the location of corneal incision based on preexisting astigmatism in phacoemulsification. Am J Ophthalmol. 2005; 139(5):767-776.

10. Özyol E, Özyol P. The relation between superior phacoemulsification incision and steep axis on astigmatic outcomes. Int Ophthalmol. 2012; 32(6):565-570.

11. Kaufmann C, Krishnan A, Landers J, Esterman A, Thiel MA, Goggin M. Astigmatic neutrality in biaxial microincision cataract surgery. $J$ Cataract Refract Surg. 2009;35(9):1555-1562.

12. Rainer G, Menapace R, Vass C, Annen D, Findl O, Schmetterer K. Corneal shape changes after temporal and superolateral $3.0 \mathrm{~mm}$ clear corneal incisions. J Cataract Refract Surg. 1999;25(8):1121-1126.

13. Kohnen S, Neuber R, Kohnen T. Effect of temporal and nasal unsutured limbal tunnel incisions on induced astigmatism after phacoemulsification. J Cataract Refract Surg. 2002;28(5):821-825.

14. Chernyak DA. Cyclotorsional eye motion occurring between wavefront measurement and refractive surgery. J Cataract Refract Surg. 2004;30(3):633-638.
15. Tjon-Fo-Sang MJ, de Faber JT, Kingma C, Beekhuis WH. Cyclotorsion: a possible cause of residual astigmatism in refractive surgery. $J$ Cataract Refract Surg. 2002;28(4):599-602.

16. Kim H, Joo CK. Ocular cyclotorsion according to body position and flap creation before laser in situ keratomileusis. J Cataract Refract Surg. 2008;34(4):557-561.

17. Fares U, Otri AM, Al-Aqaba MA, Dua HS. Correlation of central and peripheral corneal thickness in healthy corneas. Cont Lens Anterior Eye. 2012;35(1):39-45.

18. Jonuscheit S, Doughty MJ, Martin R, Río-Cristóbal A, Cruikshank V, Lang S. Peripheral nasal-temporal corneal asymmetry in relation to corneal thickness: a Scheimpflug imaging study. Ophthalmic Physiol Opt. 2015;35(1):45-51.

19. Nichamin LD. Astigmatism management at the time of phakic intraocular lenses. In: Hardten D, Davis EA, Lindstrom R, editors. Phakic Intraocular Lenses: Principles and Practice. Columbia, MN: SLACK Incorporated; 2004:57-65.

20. Thornton SP. Astigmatic keratotomy: a review of basic concepts with case reports. J Cataract Refract Surg. 1990;16(4):430-435.

21. Morlet N, Minassian D, Dart J. Astigmatism and the analysis of its surgical correction. Br J Ophthalmol. 2001;85(9):1127-1138.

22. Cravy TV. Calculation of the change in corneal astigmatism following cataract extraction. Ophthalmic Surg. 1979;10(1):38-49.

23. Alio JL, Azar DT, editors. Management of complications in refractive surgery. Berlin, Germany: Springer-Verlag; 2008:107-112.

24. Hayashi K, Yoshida M, Hayashi H. Corneal shape changes after 2.0-mm or 3.0-mm clear corneal versus sclera tunnel incision cataract surgery. Ophthalmology. 2010;117(7):1313-1323.

25. Can I, Takmaz T, Yildiz Y, Bayhan HA, Soyugelen G, Bostanci B. Coaxial, microcoaxial, and biaxial microincision cataract surgery: prospective comparative study. J Cataract Refract Surg. 2010; 36(5):740-746.

26. Hayashi K, Yoshida M, Hayashi H. Postoperative corneal shape changes: microincision versus small-incision coaxial cataract surgery. $J$ Cataract Refract Surg. 2009;35(2):233-239.

27. Barequet IS, Yu E, Vitale S, Cassard S, Azar DT, Stark WJ. Astigmatism outcomes of horizontal temporal versus nasal clear corneal incision cataract surgery. J Cataract Refract Surg. 2004;30(2):418-423.

28. Borasio E, Mehta JS, Maurino V. Surgically induced astigmatism after phacoemulsification in eyes with mild to moderate corneal astigmatism: temporal versus on-axis clear corneal incisions. J Cataract Refract Surg. 2006;32(4):565-572.

29. Boote C, Hayes S, Abahussin M, Meek KM. Mapping collagen organization in the human cornea: left and right eyes are structurally distinct. Invest Ophthalmol Vis Sci. 2006;47(3):901-908.
Clinical Ophthalmology

\section{Publish your work in this journal}

Clinical Ophthalmology is an international, peer-reviewed journal covering all subspecialties within ophthalmology. Key topics include: Optometry; Visual science; Pharmacology and drug therapy in eye diseases; Basic Sciences; Primary and Secondary eye care; Patient Safety and Quality of Care Improvements. This journal is indexed on Submit your manuscript here: http://www.dovepress.com/clinical-ophthalmology-journal

\section{Dovepress}

PubMed Central and CAS, and is the official journal of The Society of Clinical Ophthalmology (SCO). The manuscript management system is completely online and includes a very quick and fair peer-review system, which is all easy to use. Visit http://www.dovepress.com/ testimonials.php to read real quotes from published authors. 